\title{
Migración forzada: La voz de los hondureños en tránsito hacia Estados Unidos
}

Vladimir López Recinos*

\author{
Una de las desilusiones más trágicas que ocurren en América es el hecho \\ de que las personas tengan que resultar lisiadas e incluso perder la vida al verse \\ obligadas a ir en busca de un trabajo y un mejor salario para intentar sobrevivir. \\ Eso ocurre a diario en el corredor migratorio México-Estados Unidos, \\ una de las rutas donde existe mucho sufrimiento y explotación.
}

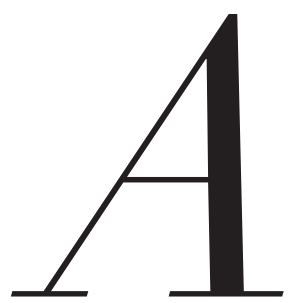

MEDIADOS Y CASI FINALES del siglo $\mathrm{XX}$, el corredor migratorio MéxicoEstados Unidos significó una salvaguarda al servir como salvoconducto para perseguidos políticos, ex combatientes guerrilleros lisiados y familias que huían de guerras, zonas bélicas, matanzas y doctrinas de seguridad impuestas o ejecutadas por algunos Estados. Hoy, ese es el itinerario más peligroso de la migración laboral indocumentada, que muchos trabajadores migrantes se ven forzados a cruzar para buscar un empleo que no tienen en

*Investigador del fenómeno de la migración centroamericana a Estados Unidos en México. sus países de origen, pero allí van dejando una o las dos piernas, un brazo y hasta su existencia. Ellos son parte del ejército laboral de reserva que está obligado a trabajar en lo que sea y bajo extremas condiciones de sobreexplotación y en la clandestinidad. En parte son resultado de la demanda y oferta de mano de obra barata considerada incluso desechable o producto del desequilibrio y asimetrías que genera la globalización neoliberal.

Evidentemente, de Sur a Norte el panorama es dantesco. Hombres y mujeres (niños, adolescentes y adultos) despedazados tras resbalar o caerse de un tren carguero en movimiento. Zonas de tolerancia donde las jóvenes son retenidas y explotadas sexualmente. Las personas y sus cuerpos son tasados como mercancías 
que tienen un costo y debe pagarse. La libertad y los derechos humanos es algo irreal para algunas autoridades y civiles que confabulados en acciones ilícitas han hecho del tráfico y trata de personas un gran negocio. Así obtienen ganancias arriba de los 32 mil millones de dólares anuales, sólo menores a las que genera el narcotráfico y el tráfico de armas, según cálculos e investigaciones de organismos de trabajo y seguridad del Departamento de Estado de Estados Unidos.

A tal situación, perfectamente puede llegar a calificársele como la esclavitud del siglo XXI. Aunque esa ruta esclavizante es sólo una prolongación, pues realmente no empieza en la frontera que divide y conecta a Norteamérica con Centroamérica, sino que tiene su origen en un ambiente de violencia, pobreza y desigualdad de los países del istmo.

Honduras expulsa a unos cien mil emigrantes cada año y alrededor de $47 \mathrm{mil}$ son deportados, la mitad vía aérea desde Estados Unidos y la otra mitad vía terrestre desde México. Durante 2012 se reportó la cifra record de 32 mil migrantes retornados desde territorio estadounidense. Eso revela que la migración sigue a pesar de los peligros y las dificultades que representa. El caso de los hondureños es el flujo que se ha vuelto más compulsivo en los últimos años. Se ha llegado a calcular anualmente entre unos 430 mil centroamericanos transitando irregularmente por México hacia Estados Unidos, pero son detenidos y deportados a sus países de origen por las autoridades de migración mexicana.

Sin duda que las cifras son insuficientes para abarcar un fenómeno que está compuesto por las historias mismas de los migrantes y su entorno social. Es difícil pretender identificar y explicar las causas y consecuencias de la migración indocumentada sólo con datos numéricos, sin que también se analicen cualitativamente ciertos aspectos claves del fenómeno como los antecedentes que dieron origen a ese comportamiento migratorio, el contexto político, social y económico del país de origen, de tránsito y de destino final. De la misma forma, las dificultades que enfrentan los migrantes en el camino.

Los y las migrantes en su periplo por caminos, carreteras, cruces fronterizos, estaciones de buses, vías férreas, albergues y centros de detención en territorio mexicano, van dejando un mar de historias muchas veces no contadas. Éstas suelen quedarse en el olvido o quedan guardadas en la memoria de ellos mismos y de quien un día las escuchó. Esos testimonios pueden ir desde lo inverosímil hasta lo más amargo y conmo- vedor. En ellos afloran aspectos importantes de la vida de los migrantes: sentimientos, deseos, anhelos, creencias e ideologías, pero también sufrimiento, angustias y mucha frustración.

Oír las historias de los y las migrantes, observar el entorno social de sus países de origen y de los de tránsito hacia Estados Unidos es una experiencia enriquecedora del proceso de investigación sobre las problemáticas que presenta el fenómeno de la migración. Además de conocerles, nos proporcionan datos e información que ayudan a ir dilucidando por qué migran, cuáles son los costos sociales y humanos del éxodo y su impacto en el desarrollo.

Un ejemplo de esos testimonios son los de Wendoly, Carlos, Omar y Jesse quienes tras varios días sin casi probar alimentos y líquidos suficientes, sorteando riesgos, peligros y pasando numerosas vicisitudes lograron llegar hasta el albergue Belén de la ciudad de Saltillo, en el estado mexicano de Coahuila fronterizo con Estados Unidos. Los nombres son reales, corresponden a Wendoly González, Carlos Hernández, Omar Reyes, Jesse Rodríguez, todos migrantes hondureños. Les hacemos un extenso agradecimiento por habernos brindado una entrevista estando aún muy cansados de andar. Sus respectivos testimonios fueron recopilados a través de entrevistas a profundidad durante el trabajo de campo en los albergues de migrantes en el noreste de México. Allí tratan de recuperarse del agotamiento, lesiones y enfermedades que contrajeron en el trayecto. Teniendo un poco de energía, seguirán de nuevo con el viaje, pero mientras llega ese momento, sentados en el patio revuelven en la memoria para compartirnos sus testimonios.

La primera mañana de abril, Wendoly, con 23 años de edad, después de estarlo pensando, decidió irse de verdad. Lo dejó todo. Familia, trabajo y estudios. Es madre soltera y con dificultades estudiaba la secundaría. Quería cursar una carrera universitaria que le permitiría conseguir un mejor trabajo para mantener a sus dos hijos. Se hastió de que el poco salario que recibía nunca le ajustara para fin de mes. Le encargó los chigüines (niños) a su madre quien con lágrimas le dio la bendición, un fuerte abrazo y le dijo: “¡cuídate por favor!". "Me pesó dejar los estudios, pero más me dolió dejar a mis hijos. Por ellos lo hice, quiero darles una mejor vida, no quiero que sufran. Usted sabe, el problema es que hay mucha pobreza, todo está caro y en los trabajos se paga poco", dice la joven.

Ella nunca antes había salido de Honduras y en su primer viaje tuvo que rodear garitas y caminar de no- 
che armada de un palo en la mano como única defensa, por zonas donde roban, violan y matan a las mujeres. Para avanzar rápido tomó un tren de carga. En el primer intento se deslizó y perdió los zapatos, pero en el segundo se aferró muy fuerte. "Sólo el que no viaja en estas condiciones no sabe lo que es sufrir. Ha sido duro, yo no me regreso después de todo lo que pasé, hay un dicho: todo sacrificio en la vida tiene su recompensa, y sé que allá en Estados Unidos de alguna manera voy a salir adelante. Algunos nos creen egoístas, pero no es así, las mujeres tenemos que luchar por lo que queremos, el problema es que no todas tienen el valor de hacerlo", dice tras recordar que a los dos años perdió a su padre y su madre enfrentó toda la carga.

$\mathrm{Al}$ igual que centenares de hondureños, Carlos, con 24 años de edad, abriga un sueño, que más bien es una necesidad básica: habitar una vivienda de cuatro paredes. Él no dormía tranquilo sabiendo lo peligroso que significaba estar con su familia en una casa de madera carcomida a la orilla de un precipicio en la colonia Altos de San Francisco, en la ciudad de Tegucigalpa, capital de Honduras. Trabajaba de lunes a domingo construyendo casas, pero lo poco que ganaba, nunca le permitió construir la suya. La desesperación de ver pasar los días y que ni una carga de ladrillos podía comprar, fue en parte lo que al experimentado obrero de la construcción lo hizo tener que emigrar hacia Estados Unidos. "Con mi esposa íbamos luchando y luchando, al principio alquilábamos luego conseguimos un terreno, pero no pasamos de la casita de madera, ni para comprar ladrillos nos ajustaba. Nuestro pensamiento no es hacer pisto (dinero) a montones, es simplemente vivir decentemente dentro de cuatro paredes que estén seguras, eso es todo lo que queremos", expresa Carlos Hernández, quien desde joven trabaja en la construcción y la carpintería para mantener a su esposa e hijo de 2 años.

Otro de los motivos que hacen a Carlos ir al norte es el desear que su mamá viva mejor. "Allá en Honduras casi todos a la deriva, los matrimonios se despedazan y se destruyen, por lo general, uno se queda sin padre y quiero ayudar a mi madre que vive en una zona muy fea y al menos comprarle un terrenito en un lugar bonito".

Durante la plática al igual que muchos de los migrantes, Carlos se queja constantemente de la corrupción, la delincuencia, del desempleo y la pobreza que impera en su país y señala a quienes él considera como los responsables de esos múltiples problemas. "Los gobernantes y los políticos tienen la culpa, porque se meten a hacer dinero, pero no miran a la pobrería, no les importa las situaciones difíciles que pasa la gente pobre. No les preocupa si la gente come o no come, si tiene trabajo o no".

$\mathrm{Al}$ dejar su hogar, Carlos prometió mandar dinero para comprar una buena casa.

Ser útil y no encontrar trabajo por más que se busque, a cualquiera le puede resultar angustiante, más aún, si se tiene una familia que mantener. Eso le pasó a Omar, de 28 años de edad, quien hasta hace unos meses atrás vivía en Tegucigalpa, junto a su esposa e hijos. Sin embargo, tuvo que dejarlos y verse obligado a irse hacia Estados Unidos en la búsqueda de un posible trabajo para así tratar de solventar la crisis económica de su hogar.

"Sí, estoy casado. Tengo dos hijos, uno de cuatro años y otro de un año. En mi país no pude encontrar trabajo. Allá caminábamos y caminábamos por toda la ciudad, pero sólo encontramos los proyectos abandonados y la gente siempre nos respondía que faltaba dinero para pagar la mano de obra", dijo el hondureño, quien desde muy joven emigró de la provincia de Choluteca a la capital, en busca de mejores perspectivas de vida y ahora ante el desempleo decidió emigrar más lejos.

"En ocasiones nos trasladamos hasta otros lugares para ver si negociábamos con algunos contratistas, pero nada, tampoco encontramos trabajo", relató Reyes, quien asegura ser un excelente profesional en las labores de la ebanistería. "Lo que más me motivó a irme a buscar trabajo a Estados Unidos fue la necesidad que uno pasa. Eso nos lleva a muchos a salir de nuestro país, porque la moneda está devaluada. También el saber que el poquito dinero que uno gana en Honduras, en Estados Unidos lo puedes ganar en horas, luego lo inviertes y sostienes la familia".

La separación no era nada fácil para Omar, hasta fue motivo de discusión con su pareja, pero al ver que su amigo Carlos se iba para Estados Unidos en la búsqueda de un empleo, él también tomó la decisión final de irse.

Jesse, de 26 años de edad. Pasó su niñez con cierta comodidad. Soñaba con viajar y conocer el mundo, pero nunca como migrante indocumentado, mucho menos arriesgando la vida a bordo de un tren carguero para irse en busca de las oportunidades que le fueron negadas en su país de origen. Con estudios del idioma inglés y sistemas de computación el joven hondureño lamenta no haber podido encontrar un empleo digno en su país. También resiente haberse separado de su 
familia y dejar a su esposa y sus dos hijas gemelas en la ciudad de San Pedro Sula.

"Ellas no querían que me viniera, pero la necesidad me hizo hacer el viaje para tratar de salir adelante, pues no encontré trabajo. Honduras es muy bonita, pero liberales y cachurecos (conservadores) han arruinado el país. No hay empleo, cada tres meses aumenta la canasta básica y los salarios no te alcanzan para educar a tu familia”, dice Jesse, quien tardó 3o días para a penas llegar al noreste de México.

En la casa del migrante Belén, relató que tuvo que subirse a varios trenes, ver de cerca la muerte, ser objeto de extorsiones, persecuciones y agresiones por parte de agentes de migración y guardias de seguridad privada que vigilan la transportación ferroviaria mexicana. "Tome el tren en Los Naranjos, allí me junte con tres compatriotas más, un chavo y dos muchachas, pero en El Ramonal nos agarró migración, dijeron que si queríamos seguir teníamos que pagar mil pesos y nos llevarían hasta otra vía donde pasaba el tren. No podíamos hacer nada, así que aceptamos". Los encuentros con migración y guardias privados de seguridad que cuidan las vías del tren fueron constantes, y le impedían a Jesse y al resto abordar los vagones. "Los policías, la migración y los garroteros nos pegaban tremendas correteadas. Ya estábamos desesperados, pues se nos pasaron muchos trenes".

Igual que los demás migrantes, durante el viaje pasó varios días sin comer y tomar agua, pero lo más espantoso del recorrido fue ver la forma como murieron las dos jóvenes compañeras de viaje a la altura de Orizaba en el estado de Veracruz. "Las muchachas se durmieron en las góndolas del tren, veníamos despertándolas a cada rato porque cuando uno viene por allí, hace un frío exagerado que casi te congela. Veníamos frotándonos la cara y las manos para no dormirnos. Ellas se cayeron y escuchamos unos gritos. Se murieron. No pudimos hacer nada".

Wendoly salió de su casa en la colonia La Joya de Tegucigalpa el i de abril con unos cuantos dólares bien escondidos en los bolsillos de su pantalón. El Í4 pasó su cumpleaños en el albergue Belén y dos días después siguió el camino para la frontera. Ella ahora está trabajando en Carolina del Norte. Carlos y Omar asistían a una iglesia de la colonia Altos de San Francisco y todas las noches después del culto se daban un tiempo para planificar el viaje. Salieron de Tegucigalpa el 2 de abril. Con sólo 450 lempiras (25 dólares) cada uno. Apenas les alcanzó para aproximarse a la frontera de Guatemala con México. Cruzaron la línea fronteriza, pero sin dinero tuvieron que caminar y luego tomaron un tren carguero. Dieciséis días después ya estaban en Saltillo. Luego siguieron adelante por la vía carretera que conduce hasta Nuevo Laredo, Tamaulipas. Su intención era cruzar la frontera norte y buscar trabajo en cualquier ciudad. No se volvió a saber nada de ellos. Jesse salió un I3 de marzo de Honduras, hasta el I2 de abril logró llegar al Albergue Belén. Una semana después siguió su camino. En la última comunicación, él nos dijo que cruzó el río Bravo y logró llegar a Estados Unidos. Nos asegura estar bien, que pudo conseguir trabajo y le está ayudando a su familia, pero dice que a veces por las noches no puede conciliar el sueño y recuerda constantemente los gritos de las dos jóvenes al caer del tren.

También en los países centroamericanos hemos tenido un acercamiento con algunos de los migrantes lisiados para conocer su historia personal y documentarla. La pérdida de una o dos de sus extremidades inferiores o superiores es algo difícil de superar. Ciertamente, el daño físico es irreparable y en algunos casos puede medio solucionarse de forma limitada con una prótesis, pero el golpe psicológico y emocional es aún mayor. Cuesta mucho asimilarlo e impide a una gran parte de los y las migrantes salir avante con sus vidas, refugiándose muchos en las drogas y el alcohol, más aún, cuando los gobiernos de los países expulsores de personas son indiferentes ante esa problemática, la sociedad los mira con desprecio, discriminación y los políticos intentan sacar provecho de la tragedia.

Eso le pasó a Manuel, quien hastiado de las injusticias de su país decidió emigrar hacia Estados Unidos de forma indocumentada para tratar de subsistir, pero sólo alcanzo a llegar hasta un pueblo del sur de México, pues allí un tren carguero le cercenó la pierna. Él y otros de sus compatriotas, ahora han pasado a ser parte del ejército laboral de reserva lisiado, que año con año ha venido incrementándose y ahora está empezando a visibilizarse en los puentes peatonales, esquinas y avenidas de las capitales y distintas ciudades de Honduras, El Salvador y Guatemala, principalmente, pues son los tres países centroamericanos que más población han expulsado hacia el norte en los últimos 20 años.

Manuel dice optimista que aún puede trabajar utilizando sus extremidades superiores, "puedo pintar muy bien”. En el brillo de sus ojos azules se nota aún la chispa de la esperanza y asegura que si alguien requiere de ese servicio y está dispuesto a pagarle lo justo, podría dejar el puente peatonal de Plaza Miraflores, 
que es el lugar donde a diario se encuentra solicitando una ayuda para vivir. También comenta que desde hace varios años ha estado buscando por distintos medios la forma de conseguir la donación de una prótesis, lo cual hasta la fecha no ha sido posible a pesar de que ha recurrido a distintas instituciones de rehabilitación y centros de salud de carácter público y privado, pero la respuesta no ha sido satisfactoria. Le ha resultado difícil alcanzar ese objetivo para poder dejar las muletas, obtener una mejor calidad de vida y poder realizar otras actividades laborales más dinámicas y productivas. Él dice estar dispuesto a poner de su parte y no darse por vencido.

Sin duda, es preocupante la indiferencia del gobierno y la sociedad hondureña en su conjunto con respecto a la migración indocumentada hacia Estados Unidos. La falta de conciencia sobre esa problemática, es evidente, y aunque ya está calando hondo, no se repara en lo más mínimo con políticas sociales y de empleo que medio contengan el éxodo.

En Honduras ya casi no se produce ni lo que se consume internamente, las finanzas están en números rojos, pero el saqueo y el derroche es insaciable y descomunal por parte de la mayoría de políticos, gobernantes y algunos empresarios, que no han estado contribuyendo al desarrollo del país durante décadas. Hoy son los migrantes hondureños, quienes en parte con su esfuerzo, están manteniendo a flote a esa pobre y quebrada nación. El caos quizá sería mayor si explotase el único salvavidas que mensualmente están inflando los mismos migrantes, que fueron directa o indirectamente expulsados y que todavía sueltan laboriosamente algunas gotas para la subsistencia. Sin embargo, eso no justifica la expulsión, exportación u oferta encubierta de mano de obra barata para las otras naciones.

El desarrollo de ese país no se logrará desde afuera y mucho menos con migrantes y remesas. Éste debe darse con fuerzas sociales, políticas y económicas en- dógenas y tiene que ser responsabilidad de todo el Estado hondureño en su conjunto. Así debe ser, aunque algunos crean que no. Es decir, el sector público crea las instituciones, las leyes, la seguridad social, la educación, etcétera, para que el sector privado pueda invertir e innovar y tomar riesgos para así ir generando un crecimiento y empleo. Ni uno ni otro deberían de ser decadentes, parásitos o depredadores, sino que debe ser una responsabilidad compartida.

¿Qué le conviene más al país y su población? Las respuestas deben tomar en cuenta que con la emigración hondureña está ocurriendo lo siguiente: I) pérdida de mano de obra; 2) recibe mano de obra lisiada; 3) recibe remesas que sólo activan la economía a través del consumo; 4) las remesas apenas sirven de paliativo a la pobreza extrema; 5) el gasto de las remesas genera riqueza y "desarrollo" para ciertos grupos, pero no es algo equitativo, y 6) es un círculo vicioso que recrudece más las asimetrías y desigualdades sociales y económicas.

¿Cómo lograr que un trabajo para los hondureños no implique un costo humano tan alto? ¿Qué hacer para que el país no siga perdiendo lo más valioso que tiene: su población joven y productiva? Estas dos interrogantes deben ser motivo de reflexión y a la vez servir para proponer algunas posibles soluciones a una problemática que es necesario atender urgentemente de forma racional y no demagógica, en caso contrario, el atraso, subdesarrollo y la miseria seguirán siendo cada vez más el rumbo que irá tomando el país. Debe buscarse un cambio significativo orientado a reactivar la poca estructura productiva interna e ir dejando la dependencia a las remesas, para mejor generar fuentes de trabajo interno mejor remunerados, porque los trabajadores migrantes indocumentados no son superhéroes ni mucho menos una especie robótica salvadora e indestructible. Es decir, no debería dársele una continuidad a un modelo de dependencia, exclusión y vulnerabilidad. 


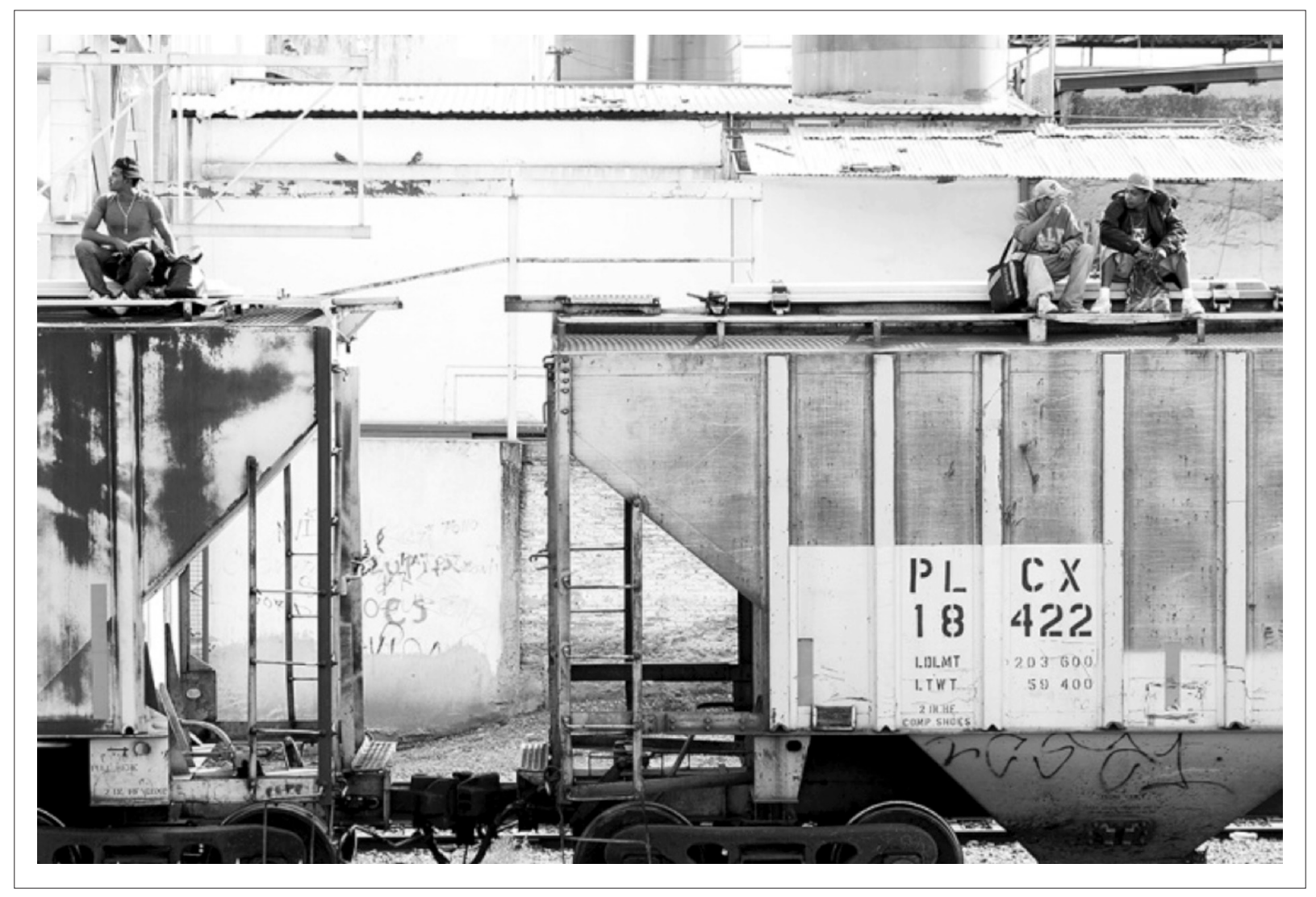

